\title{
Organellar Gene Expression and Acclimation of Plants to Environmental Stress
}

\author{
Dario Leister, Liangsheng Wang and Tatjana Kleine* \\ Plant Molecular Biology, Department Biology I, Ludwig-Maximilians-Universität München, Planegg-Martinsried, Germany
}

\section{OPEN ACCESS}

Edited by:

Adriano Nunes-Nesi,

Universidade Federal de Viçosa, Brazil

Reviewed by:

Gabriela Toledo-Ortiz,

Lancaster University, UK

Norberto Daniel lusem,

University of Buenos Aires, Argentina

${ }^{*}$ Correspondence:

Tatjana Kleine

tatjana.kleine@/mu.de

Specialty section:

This article was submitted to

Plant Physiology,

a section of the journal

Frontiers in Plant Science

Received: 20 December 2016

Accepted: 07 March 2017

Published: 21 March 2017

Citation:

Leister D, Wang $L$ and Kleine $T$

(2017) Organellar Gene Expression and Acclimation of Plants

to Environmental Stress.

Front. Plant Sci. 8:387.

doi: 10.3389/fpls.2017.00387
Organelles produce ATP and a variety of vital metabolites, and are indispensable for plant development. While most of their original gene complements have been transferred to the nucleus in the course of evolution, they retain their own genomes and gene-expression machineries. Hence, organellar function requires tight coordination between organellar gene expression (OGE) and nuclear gene expression (NGE). OGE requires various nucleus-encoded proteins that regulate transcription, splicing, trimming, editing, and translation of organellar RNAs, which necessitates nucleus-to-organelle (anterograde) communication. Conversely, changes in OGE trigger retrograde signaling that modulates NGE in accordance with the current status of the organelle. Changes in OGE occur naturally in response to developmental and environmental changes, and can be artificially induced by inhibitors such as lincomycin or mutations that perturb OGE. Focusing on the model plant Arabidopsis thaliana and its plastids, we review here recent findings which suggest that perturbations of OGE homeostasis regularly result in the activation of acclimation and tolerance responses, presumably via retrograde signaling.

Keywords: organellar gene expression, plastid, retrograde signaling, Arabidopsis, acclimation

\section{INTRODUCTION: THE PLASTID GENE-EXPRESSION MACHINERY IS OF MIXED GENETIC ORIGIN}

Like mitochondria, plastids - as descendants of cyanobacterium-like progenitors - are of endosymbiotic origin (Raven and Allen, 2003). During evolution, plastids have lost most of their genes to the nucleus, and the plastid genomes of embryophytes contain only 90 to 100 genes (Wicke et al., 2011). However, plastids contain 3000-4000 proteins which function in photosynthesis, the biosynthesis of fatty acids, amino acids, hormones, vitamins, nucleotides, and secondary metabolites, and intracellular signaling (Leister and Kleine, 2008). Thus, plastids encode only a small fraction of the proteins needed to sustain the processes they host. The relatively few genes remaining in the organelles code for proteins involved in plastid gene expression (PGE) or energy production. But while its gene complement is small, PGE is a very complex process. This is because plastids have retained a prokaryotic gene-expression apparatus which is combined with eukaryotic inventions, and its polycistronic transcripts must undergo numerous posttranscriptional maturation steps (Figure 1). In higher plants, plastid transcription is performed by three different RNA polymerases: two monomeric, nucleus-encoded (NEP) RNA polymerases and a plastid-encoded (PEP) E. coli-like enzyme (Lerbs-Mache, 2011; Börner et al., 2015). Moreover, the multisubunit enzyme requires a set of polymerase-associated proteins (PAPs) and sigma factors 


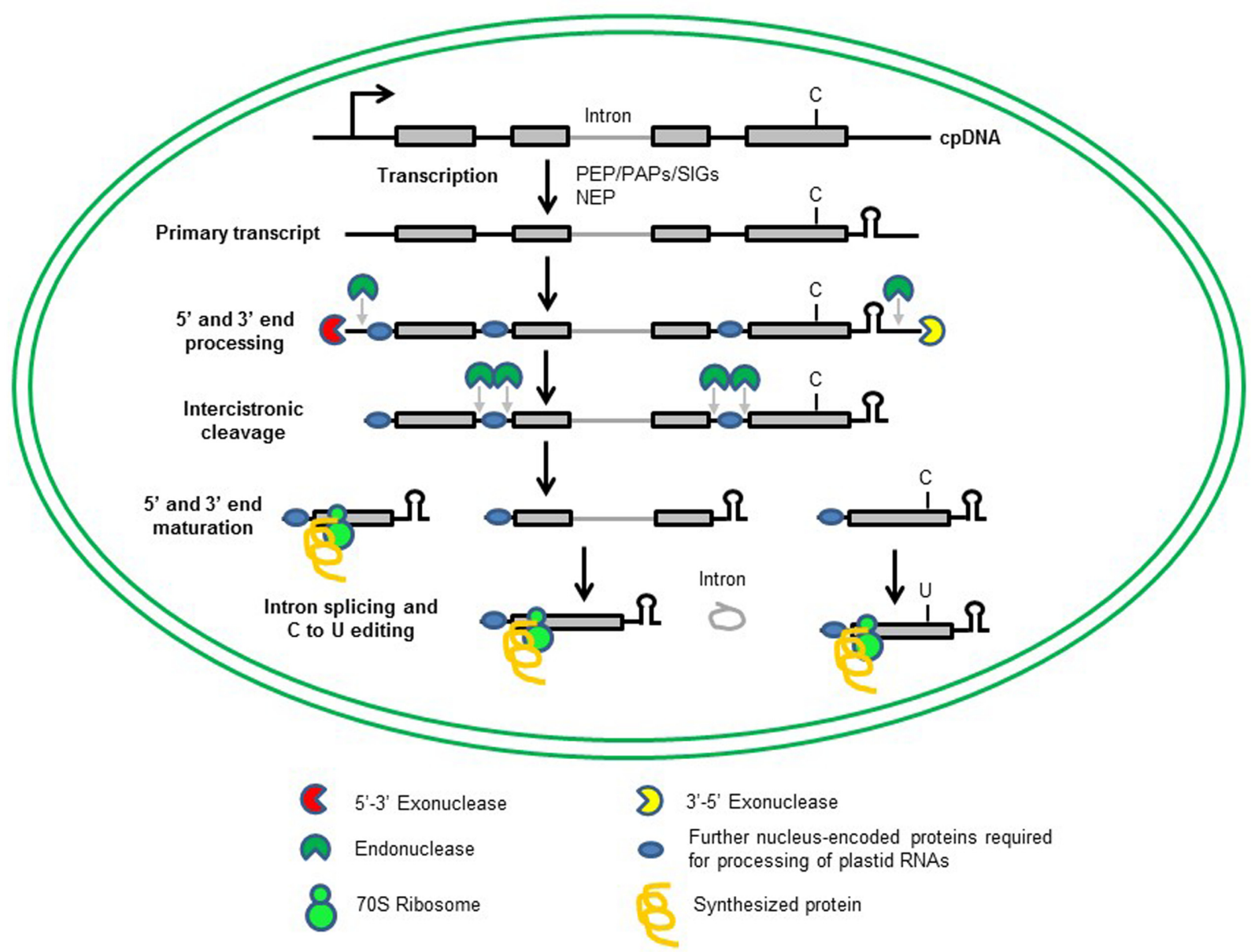

FIGURE 1 | Transcription of chloroplast genes and maturation of chloroplast RNAs. Most of the chloroplast genes are organized in operons, and are transcribed as polycistronic RNAs from single promoters (bent arrow). Transcription of chloroplast mRNA depends on two types of RNA polymerases, a plastid-encoded PEP and one or two nucleus-encoded NEPs. The primary transcript undergoes several steps of maturation that include $5^{\prime}$ and $3^{\prime}$ end processing, intercistronic cleavage, $5^{\prime}$ and $3^{\prime}$ end maturation, intron splicing and RNA editing to produce functional RNAs. For these events to take place, a whole series of nucleus-encoded proteins are needed (blue oval or segmented circles). Mature plastid RNAs are translated by bacterial-type 70S ribosomes using the set of tRNAs encoded by the plastid genome.

(SIGs) for function, which are themselves encoded in the nucleus (Lerbs-Mache, 2011; Börner et al., 2015; Chi et al., 2015).

The polycistronic RNAs synthesized by plastid polymerases require extensive processing, including $5^{\prime}$ and $3^{\prime}$ trimming, intercistronic cleavage, splicing and editing, for which a plethora of nucleus-encoded proteins are needed (Figure 1; del Campo, 2009; Stern et al., 2010; Hammani et al., 2014; Kleine and Leister, 2015; Schmitz-Linneweber et al., 2015). Plastid proteins are synthesized by bacterial-type $70 \mathrm{~S}$ ribosomes using a set of tRNAs that is entirely encoded in the plastid genome (Tiller and Bock, 2014; Sun and Zerges, 2015). The plastid ribosome itself consists of the large (50S) and small (30S) multi-component ribosomal subunits, each comprising one or more plastid-encoded ribosomal RNA species (rRNAs), and furthermore, plastid- and nuclear-encoded proteins (Yamaguchi and Subramanian, 2000; Yamaguchi et al., 2000).

\section{IMPACT OF ENVIRONMENTAL CHANGES ON THE PGE MACHINERY}

Plastid gene expression is crucial for plant development and photosynthesis, and must therefore respond appropriately to developmental and environmental changes. It does so, in part, by modifying transcription levels. Thus, the hormone abscisic acid (ABA) represses the transcription of plastid genes (Yamburenko et al., 2013), and also the circadian clock (Noordally et al., 2013), light, temperature and plastid development differentially modulate transcription in the plastid (reviewed in: Börner et al., 2015). Recently, it was proposed that light-related plastid transcriptional responses are integrated by especially SIG5 (Belbin et al., 2017). In detail, the transcriptional response to light intensity, as well as the response to the relative proportions of red and far red light through phytochrome and photosynthetic signals, and the circadian regulation of 
plastid transcription (which is predominantly dependent on blue light and cryptochrome), are regulated by SIG5 (Belbin et al., 2017). In bacteria, responses to stress rely mainly on phosphorylation-dependent signal transduction systems, which act upon transcriptional regulons either by activating DNA-binding two-component response regulators or sigma factors (Marles-Wright and Lewis, 2007). The example of the involvement of SIG5 in several light-dependent pathways (Belbin et al., 2017) and that in general, SIG5 and SIG6 are involved in multiple signaling pathways, suggest that this type of regulation may also be important in plants (reviewed in: Chi et al., 2015). Transcription rates of plastid genes have been shown to be modulated by electron-transfer inhibitors and whether incident light preferentially excites photosystem I or photosystem II (Pfannschmidt et al., 1999). Another PEP-associated protein is the plastid transcription kinase PTK, which responds to changes in the thiol/disulfide redox state mediated by glutathione (Baginsky et al., 1999), and has been shown to target SIG6 (Schweer et al., 2010). In organello run-on transcription and phosphorylation assays indeed suggest that the regulation of plastid transcription under different light intensities depends on both glutathione and phosphorylation status (Baena-Gonzalez et al., 2001).

Cluster analyses of plastid transcriptomes from mutants with severe photosynthetic defects or from plants exposed to stresses suggest that the accumulation of specific plastid RNAs is regulated in response to the physiological state of the organelle (Cho et al., 2009). Because organellar multiprotein complexes - including many components of PGE and the photosynthetic machinery - typically contain both plastid- and nucleus-encoded subunits, tight coordination of the activity of the two compartments is necessary. A part of this takes place at the transcript level, as revealed by an analysis of co-regulation based on 1300 transcription profiles obtained under different environmental conditions and in different genetic backgrounds (Leister et al., 2011). The tightest co-regulation was generally observed for genes located in the same compartment. Strikingly however, under stress conditions, nucleus-plastid coregulation could predominate over intracompartmental networks, i.e., specific sets of nuclear and organellar photosynthesis genes were co-expressed. Moreover, when genes were ranked according to the number of situations in which their expression levels were altered by at least twofold (Leister et al., 2011), NDHF (the plastid gene for a subunit of $\mathrm{NADH}$ dehydrogenase) was classified as "very highly responsive," as it reacted in 104 of 413 tested states. Several other plastid genes were highly responsive, showing that coordinated transcriptional regulation occurs on a broader scale. The relevance of transcriptional control in the plastid is underlined by changes in the expression of nucleusencoded sigma factors (which mediate transcription initiation by PEP): SIG1 and SIG5 mRNA levels are regulated in 110 and 65 conditions, respectively (Leister et al., 2011) and other studies confirm that sigma factors respond to environmental conditions and are involved in acclimation processes (see above; summarized in: Börner et al., 2015; Chi et al., 2015). Indeed, SIG5 is considered as a multiple stress-responsive sigma factor (Nagashima et al., 2004; Chi et al., 2015), because SIG5 is induced by exposure to high light, low temperature, high salt and high osmotic pressures (Nagashima et al., 2004), blue light (Tsunoyama et al., 2002), and ABA (Yamburenko et al., 2015).

Steady-state mRNA levels at any given time reflect the relationship between transcription rate and mRNA degradation rate. In bacteria, the latter plays an important role in controlling gene expression (Hui et al., 2014). Since sessile plant species cannot escape from unfavorable environmental conditions, it is conceivable that they have had to develop more flexible response mechanisms. Indeed, it is generally accepted that the control of PGE has shifted to post-transcriptional events over the course of evolution (Barkan and Goldschmidt-Clermont, 2000; Stern et al., 2010), especially in mature chloroplasts (Sun and Zerges, 2015). Thus, unlike redox regulation of transcription in mustard (Pfannschmidt et al., 1999) and ABA-mediated repression of transcriptional activity of chloroplast genes in barley (Yamburenko et al., 2013), levels of individual plastid mRNAs in spinach (Klaff and Gruissem, 1991) and barley (Kim et al., 1993) during plant development are mainly determined by alterations in stability, with half-lifes of many hours or even days - much more stable than bacterial mRNAs with typical lifetimes of seconds to hours (Radhakrishnan and Green, 2016). This suggests that the differential accumulation of chloroplast mRNAs - at least under these conditions - is primarily regulated at the post-transcriptional level. Consequently, RNA stability is probably the dominant factor governing mRNA levels in plastids. Interestingly, a genome-wide study of mRNA decay rates in A. thaliana cell cultures showed that nuclear transcripts encoding mitochondrial, chloroplast and peroxisomal proteins tend to have a high proportion of transcripts with long halflifes (Narsai et al., 2007). This may be largely due to the fact that many of the proteins known to be located in these organelles are associated with intermediate metabolism and energy. Interestingly, transcripts encoding pentatricopeptide repeat (PPR) proteins, which have short half-lifes, are exceptions to this generalization (Narsai et al., 2007). The latter finding is corroborated by an analysis of mRNA half-life changes in response to cold stress in Arabidopsis (Chiba et al., 2013). When mRNA levels vary depending on developmental stage, environmental factors or intracellular signals, earlier processing events can be the main determining factor (Monde et al., 2000). PPR proteins are important here also, for they are mainly targeted to chloroplasts and/or mitochondria and, as RNAbinding proteins, they participate in RNA editing, splicing, stability, and translation (Barkan and Small, 2014).

\section{ORGANELLAR GENE EXPRESSION AND ACCLIMATION TO ABIOTIC STRESS CONDITIONS}

Many of the genes on which plastid and mitochondrial gene expression (organellar gene expression; OGE) depends reside in the nuclear genome, which provides for direct control of OGE by nuclear factors (via "anterograde signaling"). Conversely, organelles transmit information relating to their developmental and metabolic states to the nucleus ("retrograde signaling"), 
enabling nuclear gene expression to be modulated in accordance with their physiological needs (reviewed in: Kleine et al., 2009; Chi et al., 2013; Bobik and Burch-Smith, 2015; Kleine and Leister, 2016). Retrograde signals are presumed to originate from OGE itself, the tetrapyrrole pathway, the redox state of the organelles, levels of reactive oxygen species (ROS) in the organelles (such as singlet oxygen, hydrogen peroxide, superoxide anion radicals, and hydroxyl radicals) and metabolites [such as cyclocitral, $3^{\prime}$-phophoadenosine $5^{\prime}$-phosphate (PAP) and methylerythritol cyclodiphosphate (MecPP)] (reviewed in: Kleine et al., 2009; Terry and Smith, 2013; Bobik and Burch-Smith, 2015; Colombo et al., 2016; Dietz et al., 2016). Recent research extends the previous view of retrograde signaling to mainly affect transcriptional reprogramming to also include posttranslational control, which involves the ubiquitin-proteasome system (reviewed in: Woodson, 2016). ROS signatures and metabolite signals control acclimation processes involving the alteration of gene expression and translation which is reviewed elsewhere (Dietz et al., 2016; Kleine and Leister, 2016). Furthermore, a picture emerges in which considerable cross-talk between established signaling pathways takes place. As examples, retrograde signaling pathways converge with photoreceptor pathways (Martin et al., 2016), regulation of flowering time (Feng et al., 2016) and/or hormonal signaling cascades (reviewed in: Bobik and Burch-Smith, 2015; Gollan et al., 2015). In this review, we focus on the relationship between OGE and acclimation responses to abiotic stresses.

\section{The gun Mutants, ABA, and Abiotic Stresses}

Treatment with inhibitors of OGE, such as chloramphenicol or lincomycin, or the carotenoid biosynthesis inhibitor norflurazon results in reduced expression of nuclear genes encoding plastid proteins (Oelmuller and Mohr, 1986). In the best-known screen for retrograde signaling mutants, genomes uncoupled (gun) seedlings were mutagenized and mutants that continued to express a nucleus-encoded plastid protein in the presence of norflurazon were selected (Susek et al., 1993). Recent research confirms that functioning chloroplasts are essential for plant acclimation to adverse environmental conditions (for an overview, see Table 1). Inactivation of the $\mathrm{H}$-subunit of the plastid Mg-chelatase (GUN5) results in cold $\left(4^{\circ} \mathrm{C}\right)$ sensitivity, and it was suggested that perturbation of plastid function in gun5 mutants could result in inhibition of protein synthesis and impair plant performance at low temperatures (Kindgren et al., 2015). In this context, it is postulated that enhanced tetrapyrrole biosynthesis might confer drought tolerance via ROS detoxification (reviewed in: Nagahatenna et al., 2015).

A recurring feature of oge mutants is their atypical response to ABA. The tetrapyrrole biosynthesis proteins GUN4 and GUN5 (Voigt et al., 2010) and the plastid-targeted PPR protein GUN1 (Cottage et al., 2010) enhance seedling development in the presence of ABA. On the other hand, loss of the mitochondrial PPR protein PENTATRICOPEPTIDE REPEAT PROTEIN FOR GERMINATION ON NaCl (PGN) results in hypersensitivity to ABA, glucose, and salinity (Laluk et al., 2011).
It was suggested that $p g n$ plants accumulate large amounts of ABA, and transcripts of ABA-related genes, as well as mitochondrial transcripts, are up-regulated. Levels of $A B I 4$ and ALTERNATIVE OXIDASE1a mRNAs, whose products are known for their roles in mitochondrial retrograde signaling, are particularly affected (Laluk et al., 2011). Thus, PGN is assumed to help neutralize ROS in mitochondria during abiotic and biotic stress responses, probably via retrograde signaling. Another mutant with perturbed RNA metabolism, srrp1 (S1 RNA-binding ribosomal protein 1), in which intron splicing of plastid trnL and processing of 5S rRNA were altered, does not display any visible phenotype under normal growth conditions, but seedling development is impaired in the presence of ABA (Gu et al., 2015). Furthermore, mutants lacking WHIRLY1 were shown to be less sensitive to salicylic acid and ABA during germination (Isemer et al., 2012a). The DNA-binding protein WHIRLY1 can translocate from plastids to the nucleus, making it one of the most promising candidate mediators of signaling between organelles and the nucleus (Isemer et al., 2012b). WHIRLY1 was recently proposed to serve as a redox sensor in plastid-to-nucleus retrograde signaling and to mediate cross tolerance, including acclimation responses (Foyer et al., 2014). Finally, application of ABA can partially restore mRNA expression of the nucleus-encoded plastid protein Lhcb1.2 in NF-treated wild-type plants, supporting the view that OGE and ABA signaling are interconnected (Voigt et al., 2010). Indeed, the transcription factor ABSCISIC ACID INSENSITIVE4 (ABI4) which has emerged as a central player in many signaling processes during plant development (reviewed in: Léon et al., 2012), has been directly associated with retrograde signaling (Koussevitzky et al., 2007; Giraud et al., 2009). Interestingly, it was shown more than a quarter of a century ago that, while abi mutations had no apparent effect on freezing tolerance, cold-acclimated ABA biosynthesis $(a b a)$ mutants were markedly impaired in freezing tolerance (Gilmour and Thomashow, 1991), indicating that ABA levels can affect freezing tolerance. In addition, temporal and spatial interactions of ABA with ROS signals were shown to play a key role in the regulation of systemic acquired acclimation of plants to heat stress (Suzuki et al., 2013) and ABA is required for plant acclimation to a combination of salt and heat stress (Suzuki et al., 2016). The manifold links between ABA and acclimation responses, and the $\mathrm{ABA}$ phenotypes of oge mutants, imply that a functional OGE system is essential for proper acclimation responses.

\section{The hon, soldat, and mterf Mutants in the Context of Abiotic Stresses}

Treatments with synthetic inhibitors expose plants to highly artificial conditions and are only effective if applied at an early stage of seedling development (Oelmuller and Mohr, 1986). To approximate physiological conditions more closely, a screen was designed that used a reduced concentration of norflurazon and low light levels. This resulted in the identification of happy on norflurazon (hon) mutants, which remain green in the presence of a low dose of norflurazon (Saini et al., 2011). Because some hon mutations were mapped to genes coding for a subunit of 


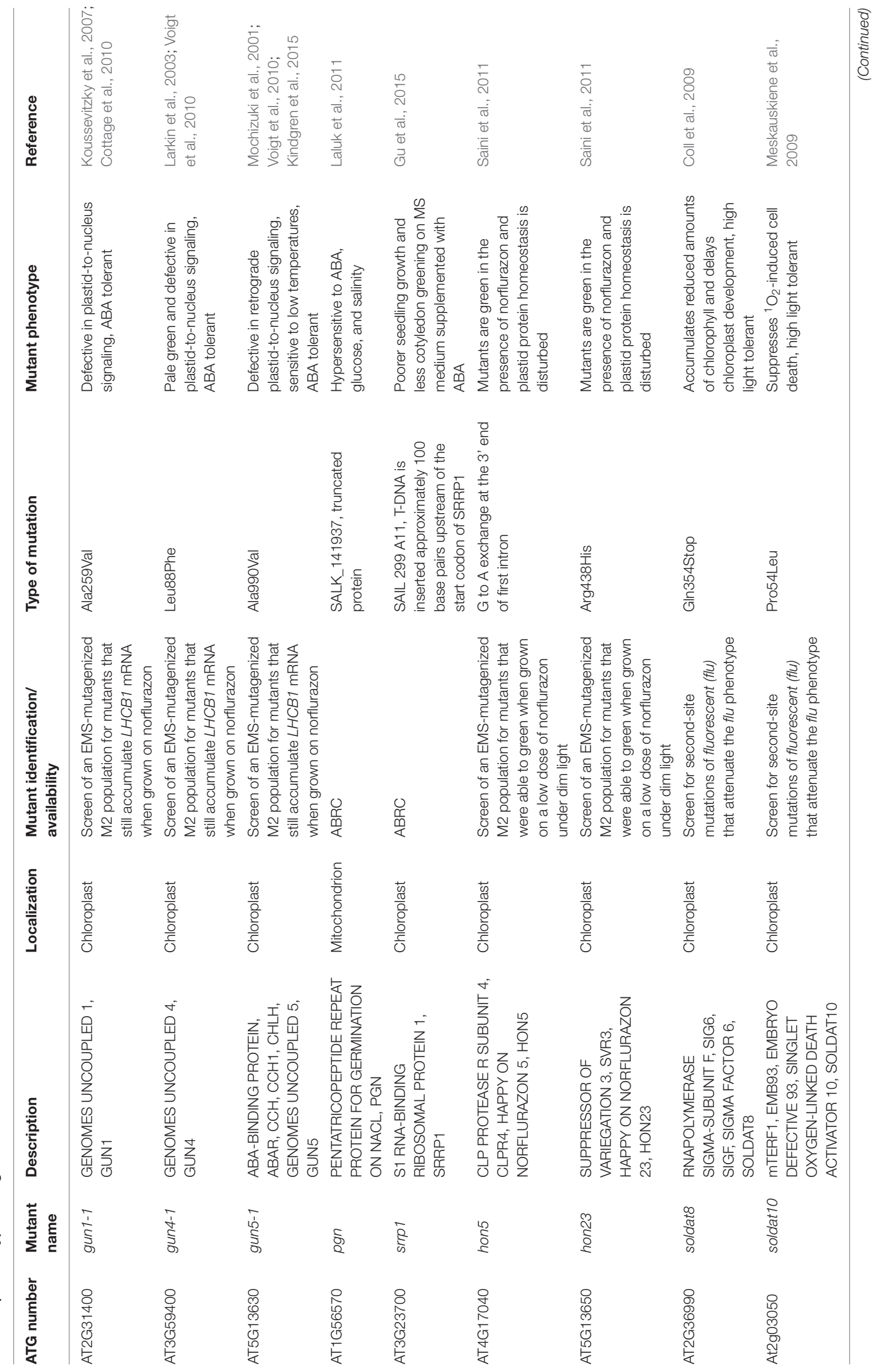




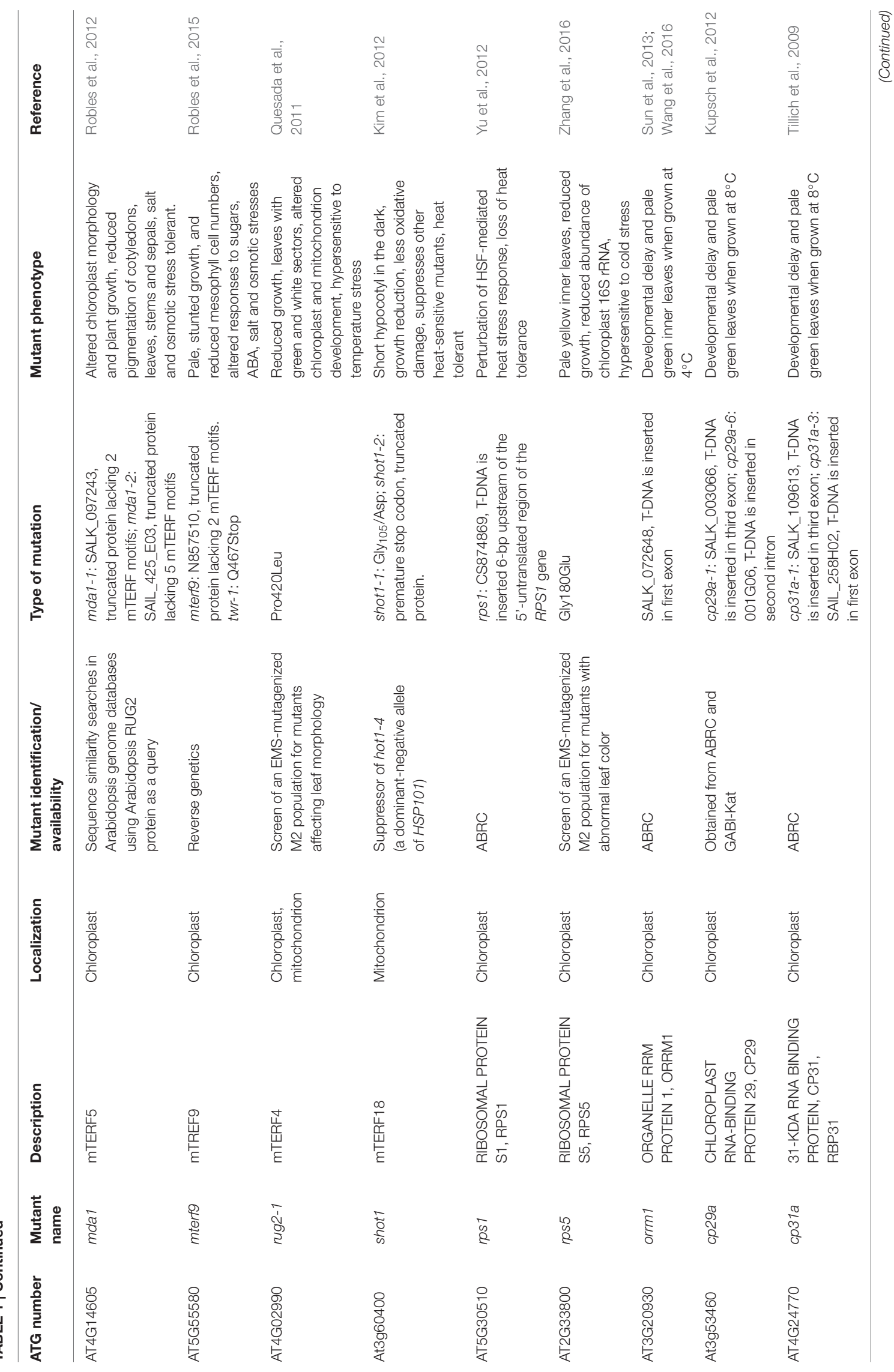




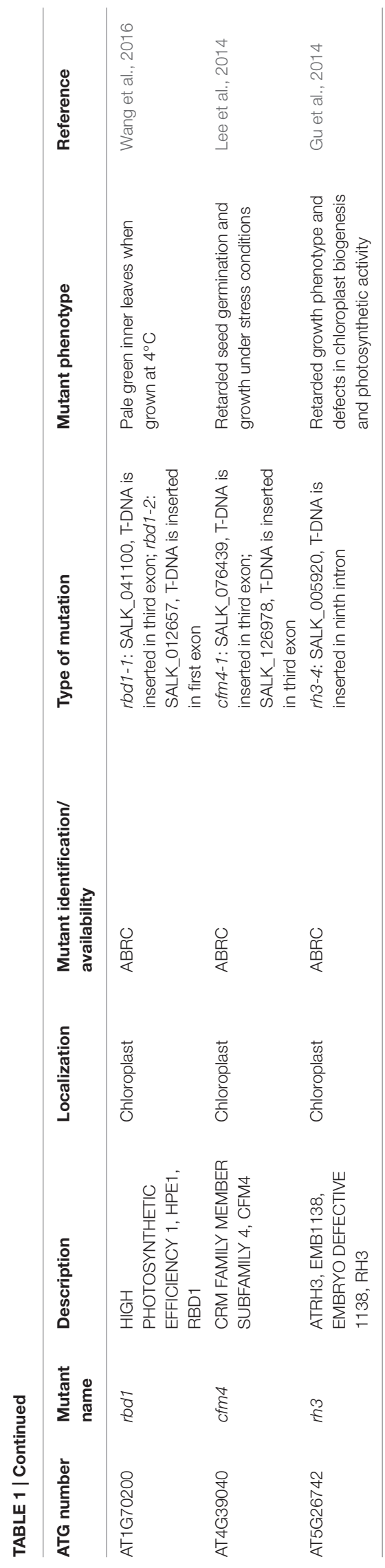

the plastid-localized Clp protease complex $(C l p R 4=H O N 5)$ and a putative plastid translation elongation factor (HON23), hon mutations can clearly interfere with PGE (Saini et al., 2011). Interestingly, hon seedlings were more resistant than WT to simultaneous exposure to low temperature and high light (Saini et al., 2011). The soldat 8 and soldat 10 (singlet oxygen-linked death activator) seedlings identified in an earlier screen for second-site mutations that suppress the singlet oxygen $\left({ }^{1} \mathrm{O}_{2}\right)$ mediated stress response of fluorescent (flu) seedlings (Coll et al., 2009; Meskauskiene et al., 2009) behave similarly. The two soldat lines are also mutated in genes for proteins related to PGE: soldat8 is mutant for SIG6 (see above; Coll et al., 2009) and soldat10 is defective in the gene encoding mitochondrial Transcription Termination Factor1 (mTERF1) (Meskauskiene et al., 2009), thus linking PGE to the ${ }^{1} \mathrm{O}_{2}$-mediated cell-death responses.

Most members of the mTERF family, which are found in metazoans (four each in human and mouse) and plants (35 in A. thaliana), are located in mitochondria and/or plastids, where they regulate OGE at different steps of transcription or translation (Kleine and Leister, 2015). Moreover, several mterf mutants have been linked to stress responses. Thus mda1 (mterf5) and mterf9 seedlings are less susceptible to salt and osmotic stresses, perhaps owing to reduced sensitivity to ABA (Robles et al., 2012, 2015). The rug2-1 (mterf4) mutant is sensitive to temperature stress. When grown at $26^{\circ} \mathrm{C}$, rug2-1 growth is arrested, whereas at $16^{\circ} \mathrm{C}$ its mutant phenotype is fully suppressed (Quesada et al., 2011). The concept of ROS as retrograde signals in heat stress responses has been reviewed elsewhere (Sun and Guo, 2016). An example for a perturbation in OGE homeostasis contributing to enhanced thermotolerance is the mterf18/shot 1 mutant (Kim et al., 2012). The mitochondrial mTERF18/SHOT1 protein was identified as a suppressor of hot 14 (a dominant-negative allele of HSP101) (Kim et al., 2012). The increase in thermotolerance (after heat acclimation at $38^{\circ} \mathrm{C}$ for $90 \mathrm{~min}$, followed by $2 \mathrm{~h}$ at $22^{\circ} \mathrm{C}$, then heat-shocked at $45^{\circ} \mathrm{C}$ for several hours) in the shot 1 mutant is associated with the accumulation of lower amounts of ROS, and thus a higher tolerance of oxidative stress. Moreover, the plastid ribosomal protein S1 (RPS1) is induced after $2 \mathrm{~h}$ of heat treatment $\left(38^{\circ} \mathrm{C}\right)$ in the dark, and down-regulation of RPS1 has been shown to severely impair the heat stress-activated expression of $H s f A 2$ and its target genes, resulting in a loss of heat tolerance (Yu et al., 2012). Interestingly, the level of RPS1 is controlled by GUN1 (Tadini et al., 2016).

\section{PGE and Chilling Tolerance}

Plastid gene expression is also important for chilling (low but not freezing temperatures; $4-12^{\circ} \mathrm{C}$ ) tolerance, as exemplified by the rps 5 mutant identified in a screen for genes required for plastid development. The missense mutation in plastid ribosomal protein S5 reduces growth rate and inner leaves remain pale yellow. Furthermore, a variety of photosystem I and II proteins, as well as plastid ribosomal proteins are underrepresented. Levels of proteins associated with stress responses to cold stress are decreased in rps5, and overexpression of plastid RPS5 improves tolerance to cold (Zhang et al., 2016). In a systematic screen of 11,000 T-DNA A. thaliana insertion mutants for genes involved 
in chilling tolerance, 54 lines defective in 49 genes had a chillingsensitive phenotype. Of these genes, 16 encode proteins with plastid localization, of which four are plastid ribonucleoproteins (RNPs) (Wang et al., 2016). Three of the 16 - ORRM1, CP29A and CP31A - were previously characterized. CP31A and CP29A (for $31-\mathrm{kD}$ and $29-\mathrm{kD}$ chloroplast protein, respectively) are required for the stability of various mRNAs at low temperatures, and under these conditions they promote specific processing steps (Kupsch et al., 2012). The organelle RNA recognition motif (RRM) protein 1 (ORRM1) is an essential plastid editing factor in $A$. thaliana and maize (Sun et al., 2013). The newly identified RRM/RBD/RNP protein RBD1 binds directly to $23 \mathrm{~S}$ rRNA, and more strongly under chilling conditions than at normal growth temperatures. Accordingly, the rbd1 defect in chloroplast protein synthesis is particularly severe at low temperatures (Wang et al., 2016). Furthermore, the CRM (chloroplast RNA splicing and ribosome maturation) family member subfamily4 CFM4 (Lee et al., 2014) and the DEADbox RNA helicase RH3 ( $\mathrm{Gu}$ et al., 2014) play a positive role in seed germination and seedling growth under salt or cold stress conditions, because seed germination and seedling growth of the respective mutants are retarded under those conditions.

\section{CONCLUSION}

The importance of OGE in stress acclimation responses has become increasingly apparent in recent years. Perturbations in OGE homeostasis trigger abiotic acclimation and tolerance

\section{REFERENCES}

Baena-Gonzalez, E., Baginsky, S., Mulo, P., Summer, H., Aro, E. M., and Link, G. (2001). Chloroplast transcription at different light intensities. Glutathione-mediated phosphorylation of the major RNA polymerase involved in redox-regulated organellar gene expression. Plant Physiol. 127, 1044-1052. doi: $10.1104 /$ pp.010168

Baginsky, S., Tiller, K., Pfannschmidt, T., and Link, G. (1999). PTK, the chloroplast RNA polymerase-associated protein kinase from mustard (Sinapis alba), mediates redox control of plastid in vitro transcription. Plant Mol. Biol. 39, 1013-1023. doi: 10.1023/A:1006177807844

Barkan, A., and Goldschmidt-Clermont, M. (2000). Participation of nuclear genes in chloroplast gene expression. Biochimie 82, 559-572. doi: 10.1016/S03009084(00)00602-7

Barkan, A., and Small, I. (2014). Pentatricopeptide repeat proteins in plants. Annu. Rev. Plant Biol. 65, 415-442. doi: 10.1146/annurev-arplant-050213040159

Belbin, F. E., Noordally, Z. B., Wetherill, S. J., Atkins, K. A., Franklin, K. A., and Dodd, A. N. (2017). Integration of light and circadian signals that regulate chloroplast transcription by a nuclear-encoded sigma factor. New Phytol. 213, 727-738. doi: 10.1111/nph.14176

Bobik, K., and Burch-Smith, T. M. (2015). Chloroplast signaling within, between and beyond cells. Front. Plant Sci. 6:781. doi: 10.3389/fpls.2015. 00781

Börner, T., Aleynikova, A. Y., Zubo, Y. O., and Kusnetsov, V. V. (2015). Chloroplast RNA polymerases: role in chloroplast biogenesis. Biochim. Biophys. Acta 1847, 761-769. doi: 10.1016/j.bbabio.2015.02.004

Chi, W., He, B., Mao, J., Jiang, J., and Zhang, L. (2015). Plastid sigma factors: their individual functions and regulation in transcription. Biochim. Biophys. Acta 1847, 770-778. doi: 10.1016/j.bbabio.2015.01.001 responses, presumably via retrograde signaling. Thus, further studies on the molecular and physiological functions of OGE proteins should elucidate their roles in such responses. Moreover, as changes in proteins responsive to stress do not always reflect changes at the transcript level, posttranscriptional and translational mechanisms must be given more attention. Cellfractionation experiments, together with metabolomics studies and the application of next-generation sequencing technologies like mRNA-Seq, global run-on (GRO)-Seq and global ribosomal profiling (Ribo-Seq), should ultimately allow us to assemble an integrated picture of how environmental changes regulate subcellular states and reveal the extent and nature of retrograde signal transduction.

\section{AUTHOR CONTRIBUTIONS}

TK drafted the manuscript, LW prepared the figure and the table, DL and TK finalized the manuscript.

\section{FUNDING}

This work was supported by the Deutsche Forschungsgemeinschaft (TRR175, project C01 and C05).

\section{ACKNOWLEDGMENT}

We thank Paul Hardy for critical reading of the manuscript.

Chi, W., Sun, X., and Zhang, L. (2013). Intracellular signaling from plastid to nucleus. Annu. Rev. Plant Biol. 64, 559-582. doi: 10.1146/annurev-arplant050312-120147

Chiba, Y., Mineta, K., Hirai, M. Y., Suzuki, Y., Kanaya, S., Takahashi, H., et al. (2013). Changes in mRNA stability associated with cold stress in Arabidopsis cells. Plant Cell Physiol. 54, 180-194. doi: 10.1093/pcp/ pcs 164

Cho, W. K., Geimer, S., and Meurer, J. (2009). Cluster analysis and comparison of various chloroplast transcriptomes and genes in Arabidopsis thaliana. DNA Res. 16, 31-44. doi: 10.1093/dnares/dsn031

Coll, N. S., Danon, A., Meurer, J., Cho, W. K., and Apel, K. (2009). Characterization of soldat8, a suppressor of singlet oxygen-induced cell death in Arabidopsis seedlings. Plant Cell Physiol. 50, 707-718. doi: 10.1093/pcp/pcp036

Colombo, M., Tadini, L., Peracchio, C., Ferrari, R., and Pesaresi, P. (2016). GUN1, a jack-of-all-trades in chloroplast protein homeostasis and signaling. Front. Plant Sci. 7:1427. doi: 10.3389/fpls.2016.01427

Cottage, A., Mott, E. K., Kempster, J. A., and Gray, J. C. (2010). The Arabidopsis plastid-signalling mutant gun1 (genomes uncoupled1) shows altered sensitivity to sucrose and abscisic acid and alterations in early seedling development. J. Exp. Bot. 61, 3773-3786. doi: 10.1093/jxb/erq186

del Campo, E. M. (2009). Post-transcriptional control of chloroplast gene expression. Gene Regul. Syst. Bio. 3, 31-47.

Dietz, K. J., Turkan, I., and Krieger-Liszkay, A. (2016). Redox- and reactive oxygen species-dependent signaling into and out of the photosynthesizing chloroplast. Plant Physiol. 171, 1541-1550. doi: 10.1104/pp.16.00375

Feng, P., Guo, H., Chi, W., Chai, X., Sun, X., Xu, X., et al. (2016). Chloroplast retrograde signal regulates flowering. Proc. Natl. Acad. Sci. U.S.A. 113, 10708-10713. doi: 10.1073/pnas.1521599113

Foyer, C. H., Karpinska, B., and Krupinska, K. (2014). The functions of WHIRLY1 and REDOX-RESPONSIVE TRANSCRIPTION FACTOR 1 in cross tolerance 
responses in plants: a hypothesis. Philos. Trans. R. Soc. Lond. B Biol. Sci. 369:20130226. doi: 10.1098/rstb.2013.0226

Gilmour, S. J., and Thomashow, M. F. (1991). Cold acclimation and cold-regulated gene expression in ABA mutants of Arabidopsis thaliana. Plant Mol. Biol. 17, 1233-1240. doi: 10.1007/BF00028738

Giraud, E., Van Aken, O., Ho, L. H., and Whelan, J. (2009). The transcription factor $\mathrm{ABI} 4$ is a regulator of mitochondrial retrograde expression of ALTERNATIVE OXIDASE1a. Plant Physiol. 150, 1286-1296. doi: 10.1104/pp.109. 139782

Gollan, P. J., Tikkanen, M., and Aro, E. M. (2015). Photosynthetic light reactions: integral to chloroplast retrograde signalling. Curr. Opin. Plant Biol. 27, 180-191. doi: 10.1016/j.pbi.2015.07.006

Gu, L., Jung, H. J., Kim, B. M., Xu, T., Lee, K., Kim, Y. O., et al. (2015). A chloroplast-localized S1 domain-containing protein SRRP1 plays a role in Arabidopsis seedling growth in the presence of ABA. J. Plant Physiol. 189, 34-41. doi: 10.1016/j.jplph.2015.10.003

Gu, L., Xu, T., Lee, K., Lee, K. H., and Kang, H. (2014). A chloroplastlocalized DEAD-box RNA helicaseAtRH3 is essential for intron splicing and plays an important role in the growth and stress response in Arabidopsis thaliana. Plant Physiol. Biochem. 82, 309-318. doi: 10.1016/j.plaphy.2014. 07.006

Hammani, K., Bonnard, G., Bouchoucha, A., Gobert, A., Pinker, F., Salinas, T., et al. (2014). Helical repeats modular proteins are major players for organelle gene expression. Biochimie 100, 141-150. doi: 10.1016/j.biochi.2013.08.031

Hui, M. P., Foley, P. L., and Belasco, J. G. (2014). Messenger RNA degradation in bacterial cells. Annu. Rev. Genet. 48, 537-559. doi: 10.1146/annurev-genet120213-092340

Isemer, R., Krause, K., Grabe, N., Kitahata, N., Asami, T., and Krupinska, K. (2012a). Plastid located WHIRLY1 enhances the responsiveness of Arabidopsis seedlings toward abscisic acid. Front. Plant Sci. 3:283. doi: 10.3389/fpls.2012. 00283

Isemer, R., Mulisch, M., Schafer, A., Kirchner, S., Koop, H. U., and Krupinska, K. (2012b). Recombinant Whirly1 translocates from transplastomic chloroplasts to the nucleus. FEBS Lett. 586, 85-88. doi: 10.1016/j.febslet.2011.11.029

Kim, M., Christopher, D. A., and Mullet, J. E. (1993). Direct evidence for selective modulation of psbA, rpoA, rbcL and 16S RNA stability during barley chloroplast development. Plant Mol. Biol. 22, 447-463. doi: 10.1007/ BF00015975

Kim, M., Lee, U., Small, I., des Francs-Small, C. C., and Vierling, E. (2012). Mutations in an Arabidopsis mitochondrial transcription termination factorrelated protein enhance thermotolerance in the absence of the major molecular chaperone HSP101. Plant Cell 24, 3349-3365. doi: 10.1105/tpc.112.101006

Kindgren, P., Dubreuil, C., and Strand, A. (2015). The recovery of plastid function is required for optimal response to low temperatures in Arabidopsis. PLoS ONE 10:e0138010. doi: 10.1371/journal.pone.0138010

Klaff, P., and Gruissem, W. (1991). Changes in chloroplast mRNA stability during leaf development. Plant Cell 3, 517-529. doi: 10.1105/tpc.3.5.517

Kleine, T., and Leister, D. (2015). Emerging functions of mammalian and plant mTERFs. Biochim. Biophys. Acta 1847, 786-797. doi: 10.1016/j.bbabio.2014. 12.009

Kleine, T., and Leister, D. (2016). Retrograde signaling: organelles go networking. Biochim. Biophys. Acta 1857, 1313-1325. doi: 10.1016/j.bbabio.2016.03.017

Kleine, T., Voigt, C., and Leister, D. (2009). Plastid signalling to the nucleus: messengers still lost in the mists? Trends Genet. 25, 185-192. doi: 10.1016/j.tig. 2009.02.004

Koussevitzky, S., Stanne, T. M., Peto, C. A., Giap, T., Sjogren, L. L., Zhao, Y., et al. (2007). An Arabidopsis thaliana virescent mutant reveals a role for ClpR1 in plastid development. Plant Mol. Biol. 63, 85-96. doi: 10.1007/s11103-0069074-2

Kupsch, C., Ruwe, H., Gusewski, S., Tillich, M., Small, I., and SchmitzLinneweber, C. (2012). Arabidopsis chloroplast RNA binding proteins CP31A and CP29A associate with large transcript pools and confer cold stress tolerance by influencing multiple chloroplast RNA processing steps. Plant Cell 24, 4266-4280. doi: 10.1105/tpc.112.103002

Laluk, K., Abuqamar, S., and Mengiste, T. (2011). The Arabidopsis mitochondrialocalized pentatricopeptide repeat protein PGN functions in defense against necrotrophic fungi and abiotic stress tolerance. Plant Physiol. 156, 2053-2068. doi: $10.1104 /$ pp.111.177501
Larkin, R. M., Alonso, J. M., Ecker, J. R., and Chory, J. (2003). GUN4, a regulator of chlorophyll synthesis and intracellular signaling. Science 299, 902-906. doi: $10.1126 /$ science. 1079978

Lee, K., Lee, H. J., Kim, D. H., Jeon, Y., Pai, H. S., and Kang, H. (2014). A nuclear-encoded chloroplast protein harboring a single CRM domain plays an important role in the Arabidopsis growth and stress response. BMC Plant Biol. 14:98. doi: 10.1186/1471-2229-14-98

Leister, D., and Kleine, T. (2008). Towards a comprehensive catalog of chloroplast proteins and their interactions. Cell Res 18, 1081-1083. doi: 10.1038/cr.2008.297

Leister, D., Wang, X., Haberer, G., Mayer, K. F., and Kleine, T. (2011). Intracompartmental and intercompartmental transcriptional networks coordinate the expression of genes for organellar functions. Plant Physiol. 157, 386-404. doi: 10.1104/pp.111.177691

Léon, P., Gregorio, J., and Cordoba, E. (2012). ABI4 and its role in chloroplast retrograde communication. Front. Plant Sci. 3:304. doi: 10.3389/fpls.2012.00304

Lerbs-Mache, S. (2011). Function of plastid sigma factors in higher plants: regulation of gene expression or just preservation of constitutive transcription? Plant Mol. Biol. 76, 235-249. doi: 10.1007/s11103-010-9714-4

Marles-Wright, J., and Lewis, R. J. (2007). Stress responses of bacteria. Curr. Opin. Struct. Biol. 17, 755-760. doi: 10.1016/j.sbi.2007.08.004

Martin, G., Leivar, P., Ludevid, D., Tepperman, J. M., Quail, P. H., and Monte, E. (2016). Phytochrome and retrograde signalling pathways converge to antagonistically regulate a light-induced transcriptional network. Nat. Commun. 7:11431. doi: 10.1038/ncomms11431

Meskauskiene, R., Wursch, M., Laloi, C., Vidi, P. A., Coll, N. S., Kessler, F., et al. (2009). A mutation in the Arabidopsis mTERF-related plastid protein SOLDAT10 activates retrograde signaling and suppresses (1) $\mathrm{O}(2)$-induced cell death. Plant J. 60, 399-410. doi: 10.1111/j.1365-313X.2009.03965.x

Mochizuki, N., Brusslan, J. A., Larkin, R., Nagatani, A., and Chory, J. (2001). Arabidopsis genomes uncoupled 5 (GUN5) mutant reveals the involvement of $\mathrm{Mg}$-chelatase $\mathrm{H}$ subunit in plastid-to-nucleus signal transduction. Proc. Natl. Acad. Sci. U.S.A. 98, 2053-2058. doi: 10.1073/pnas.98.4.2053

Monde, R. A., Schuster, G., and Stern, D. B. (2000). Processing and degradation of chloroplast mRNA. Biochimie 82, 573-582. doi: 10.1016/S0300-9084(00) 00606-4

Nagahatenna, D. S., Langridge, P., and Whitford, R. (2015). Tetrapyrrole-based drought stress signalling. Plant Biotechnol. J. 13, 447-459. doi: 10.1111/pbi. 12356

Nagashima, A., Hanaoka, M., Shikanai, T., Fujiwara, M., Kanamaru, K., Takahashi, H., et al. (2004). The multiple-stress responsive plastid sigma factor, SIG5, directs activation of the psbD blue light-responsive promoter (BLRP) in Arabidopsis thaliana. Plant Cell Physiol. 45, 357-368. doi: 10.1093/pcp/pch050

Narsai, R., Howell, K. A., Millar, A. H., O’Toole, N., Small, I., and Whelan, J. (2007). Genome-wide analysis of mRNA decay rates and their determinants in Arabidopsis thaliana. Plant Cell 19, 3418-3436. doi: 10.1105/tpc.107.055046

Noordally, Z. B., Ishii, K., Atkins, K. A., Wetherill, S. J., Kusakina, J., Walton, E. J., et al. (2013). Circadian control of chloroplast transcription by a nuclearencoded timing signal. Science 339, 1316-1319. doi: 10.1126/science.1230397

Oelmuller, R., and Mohr, H. (1986). Photooxidative destruction of chloroplasts and its consequences for expression of nuclear genes. Planta 167, 106-113. doi: $10.1007 / \mathrm{BF} 00446376$

Pfannschmidt, T., Nilsson, A., Tullberg, A., Link, G., and Allen, J. F. (1999). Direct transcriptional control of the chloroplast genes psbA and psaAB adjusts photosynthesis to light energy distribution in plants. IUBMB Life 48, 271-276. doi: 10.1080/713803507

Quesada, V., Sarmiento-Manus, R., Gonzalez-Bayon, R., Hricova, A., PerezMarcos, R., Gracia-Martinez, E., et al. (2011). Arabidopsis RUGOSA2 encodes an mTERF family member required for mitochondrion, chloroplast and leaf development. Plant J. 68, 738-753. doi: 10.1111/j.1365-313X.2011.04726.x

Radhakrishnan, A., and Green, R. (2016). Connections underlying translation and mRNA stability. J. Mol. Biol. 428, 3558-3564. doi: 10.1016/j.jmb.2016.05.025

Raven, J. A., and Allen, J. F. (2003). Genomics and chloroplast evolution: what did cyanobacteria do for plants? Genome Biol. 4:209.

Robles, P., Micol, J. L., and Quesada, V. (2012). Arabidopsis MDA1, a nuclearencoded protein, functions in chloroplast development and abiotic stress responses. PLoS ONE 7:e42924. doi: 10.1371/journal.pone.0042924

Robles, P., Micol, J. L., and Quesada, V. (2015). Mutations in the plant-conserved MTERF9 alter chloroplast gene expression, development and tolerance to 
abiotic stress in Arabidopsis thaliana. Physiol. Plant. 154, 297-313. doi: 10.1111/ ppl.12307

Saini, G., Meskauskiene, R., Pijacka, W., Roszak, P., Sjogren, L. L., Clarke, A. K., et al. (2011). 'happy on norflurazon' (hon) mutations implicate perturbance of plastid homeostasis with activating stress acclimatization and changing nuclear gene expression in norflurazon-treated seedlings. Plant J. 65, 690-702. doi: 10.1111/j.1365-313X.2010.04454.x

Schmitz-Linneweber, C., Lampe, M. K., Sultan, L. D., and OstersetzerBiran, O. (2015). Organellar maturases: a window into the evolution of the spliceosome. Biochim. Biophys. Acta 1847, 798-808. doi: 10.1016/j.bbabio.2015. 01.009

Schweer, J., Turkeri, H., Link, B., and Link, G. (2010). AtSIG6, a plastid sigma factor from Arabidopsis, reveals functional impact of cpCK2 phosphorylation. Plant J. 62, 192-202. doi: 10.1111/j.1365-313X.2010.04138.x

Stern, D. B., Goldschmidt-Clermont, M., and Hanson, M. R. (2010). Chloroplast RNA metabolism. Annu. Rev. Plant Biol. 61, 125-155. doi: 10.1146/annurevarplant-042809-112242

Sun, A. Z., and Guo, F. Q. (2016). Chloroplast retrograde regulation of heat stress responses in plants. Front. Plant Sci. 7:398. doi: 10.3389/fpls.2016.00398

Sun, T., Germain, A., Giloteaux, L., Hammani, K., Barkan, A., Hanson, M. R., et al. (2013). An RNA recognition motif-containing protein is required for plastid RNA editing in Arabidopsis and maize. Proc. Natl. Acad. Sci. U.S.A. 110, E1169-E1178. doi: 10.1073/pnas.1220162110

Sun, Y., and Zerges, W. (2015). Translational regulation in chloroplasts for development and homeostasis. Biochim. Biophys. Acta 1847, 809-820. doi: 10.1016/j.bbabio.2015.05.008

Susek, R. E., Ausubel, F. M., and Chory, J. (1993). Signal transduction mutants of arabidopsis uncouple nuclear $C A B$ and $R B C S$ gene expression from chloroplast development. Cell 74, 787-799. doi: 10.1016/0092-8674(93) 90459-4

Suzuki, N., Bassil, E., Hamilton, J. S., Inupakutika, M. A., Zandalinas, S. I., Tripathy, D., et al. (2016). ABA is required for plant acclimation to a combination of salt and heat stress. PLOS ONE 11:e0147625. doi: 10.1371/ journal.pone.0147625

Suzuki, N., Miller, G., Salazar, C., Mondal, H. A., Shulaev, E., Cortes, D. F., et al. (2013). Temporal-spatial interaction between reactive oxygen species and abscisic acid regulates rapid systemic acclimation in plants. Plant Cell 25, 3553-3569. doi: 10.1105/tpc.113.114595

Tadini, L., Pesaresi, P., Kleine, T., Rossi, F., Guljamow, A., Sommer, F., et al. (2016). GUN1 controls accumulation of the plastid ribosomal protein S1 at the protein level and interacts with proteins involved in plastid protein homeostasis. Plant Physiol. 170, 1817-1830. doi: 10.1104/pp.15.02033

Terry, M. J., and Smith, A. G. (2013). A model for tetrapyrrole synthesis as the primary mechanism for plastid-to-nucleus signaling during chloroplast biogenesis. Front. Plant Sci. 4:14. doi: 10.3389/fpls.2013.00014

Tiller, N., and Bock, R. (2014). The translational apparatus of plastids and its role in plant development. Mol. Plant 7, 1105-1120. doi: 10.1093/mp/ssu022

Tillich, M., Hardel, S. L., Kupsch, C., Armbruster, U., Delannoy, E., Gualberto, J. M., et al. (2009). Chloroplast ribonucleoprotein CP31A is required for editing and stability of specific chloroplast mRNAs. Proc. Natl. Acad. Sci. U.S.A. 106, 6002-6007. doi: 10.1073/pnas.0808529106
Tsunoyama, Y., Morikawa, K., Shiina, T., and Toyoshima, Y. (2002). Blue light specific and differential expression of a plastid sigma factor, Sig5 in Arabidopsis thaliana. FEBS Lett. 516, 225-228. doi: 10.1016/S0014-5793(02)02538-3

Voigt, C., Oster, U., Bornke, F., Jahns, P., Dietz, K. J., Leister, D., et al. (2010). Indepth analysis of the distinctive effects of norflurazon implies that tetrapyrrole biosynthesis, organellar gene expression and ABA cooperate in the GUN-type of plastid signalling. Physiol. Plant 138, 503-519. doi: 10.1111/j.1399-3054.2009. 01343.x

Wang, S., Bai, G., Wang, S., Yang, L., Yang, F., Wang, Y., et al. (2016). Chloroplast RNA-binding protein RBD1 promotes chilling tolerance through $23 \mathrm{~S}$ rRNA processing in Arabidopsis. PLoS Genet. 12:e1006027. doi: 10.1371/journal.pgen. 1006027

Wicke, S., Schneeweiss, G. M., dePamphilis, C. W., Muller, K. F., and Quandt, D. (2011). The evolution of the plastid chromosome in land plants: gene content, gene order, gene function. Plant Mol. Biol. 76, 273-297. doi: 10.1007/s11103011-9762-4

Woodson, J. D. (2016). Chloroplast quality control - balancing energy production and stress. New Phytol. 212, 36-41. doi: 10.1111/nph.14134

Yamaguchi, K., and Subramanian, A. R. (2000). The plastid ribosomal proteins. Identification of all the proteins in the $50 \mathrm{~S}$ subunit of an organelle ribosome (chloroplast). J. Biol. Chem. 275, 28466-28482. doi: 10.1074/jbc.M005012200

Yamaguchi, K., von Knoblauch, K., and Subramanian, A. R. (2000). The plastid ribosomal proteins. Identification of all the proteins in the $30 \mathrm{~S}$ subunit of an organelle ribosome (chloroplast). J. Biol. Chem. 275, 28455-28465. doi: 10.1074/ jbc.M004350200

Yamburenko, M. V., Zubo, Y. O., and Börner, T. (2015). Abscisic acid affects transcription of chloroplast genes via protein phosphatase $2 \mathrm{C}$-dependent activation of nuclear genes: repression by guanosine- $3^{\prime}-5^{\prime}$-bisdiphosphate and activation by sigma factor 5. Plant J. 82, 1030-1041. doi: 10.1111/tpj.12876

Yamburenko, M. V., Zubo, Y. O., Vankova, R., Kusnetsov, V. V., Kulaeva, O. N., and Börner, T. (2013). Abscisic acid represses the transcription of chloroplast genes. J. Exp. Bot. 64, 4491-4502. doi: 10.1093/jxb/ert258

Yu, H. D., Yang, X. F., Chen, S. T., Wang, Y. T., Li, J. K., Shen, Q., et al. (2012). Downregulation of chloroplast RPS1 negatively modulates nuclear heatresponsive expression of HsfA2 and its target genes in Arabidopsis. PLoS Genet. 8:e1002669. doi: 10.1371/journal.pgen.1002669

Zhang, J., Yuan, H., Yang, Y., Fish, T., Lyi, S. M., Thannhauser, T. W., et al. (2016). Plastid ribosomal protein S5 is involved in photosynthesis, plant development, and cold stress tolerance in Arabidopsis. J. Exp. Bot. 67, 2731-2744. doi: $10.1093 /$ jxb/erw106

Conflict of Interest Statement: The authors declare that the research was conducted in the absence of any commercial or financial relationships that could be construed as a potential conflict of interest.

Copyright (C) 2017 Leister, Wang and Kleine. This is an open-access article distributed under the terms of the Creative Commons Attribution License (CC BY). The use, distribution or reproduction in other forums is permitted, provided the original author(s) or licensor are credited and that the original publication in this journal is cited, in accordance with accepted academic practice. No use, distribution or reproduction is permitted which does not comply with these terms. 